\title{
Genetic variability and environmental variability in the estuarine isopod Sphaeroma rugicauda
}

\author{
M. J. Willis and \\ D. J. Heath
} Department of Biology, University of Essex,
Colchester, England.

Two natural populations experiencing similar variation in temperature and salinity were found to differ in their degree of colour polymorphism. The levels around which salinities varied were, however, different and the population exposed to lower, more extreme, salinities was less genetically variable. Here, the recessive Grey morph was at a high frequency and a variety of dominant "colour" morphs occurred at lower frequencies. Laboratory studies showed that the Grey morph was the more flexible and survived low salinities better than other morphs. These differences were correlated with, and affected by, environmentally induced differences in body size between populations. Individuals in highly polymorphic populations tended to be larger and the survival advantage of Grey was less in large animals than in small. These findings are discussed in the light of theories which relate genetic variability to environmental variability.

\section{INTRODUCTION}

Although spatial environmental variability is thought to exert an effect on the level of genetic variability in populations the role of temporal environmental variability is less clear (Hedrick et al., 1976). Some workers, e.g. Levins (1968) and Grasslé (1972), have suggested that increasing temporal variability would lead to increasing genetic variability. Either coarse grained (variable) environments will favour different alleles in different patches or greater ecological amplitude selects for greater biochemical flexibility which is achieved by individual heterozygosity, see Soulé (1976) for a summary. However, Battaglia (1958) and Battaglia et al. (1978) proposed that the greater flexibility required in more variable environments might be produced by the fixation of a few generalist alleles leading to low variability. Theoretical models (Hedrick et al., 1976) indicate that temporal environmental variability is less effective at maintaining genetic variation than spatial environmental variability.

Surveys of the levels of allozyme variation have failed to support these suggestions which considered physical, abiotic, environmental factors as the most important determinants of genetic variability. Invertebrate populations from the deep sea, and arctic and tropical oceans (all classified as environments of low abiotic variability) have respectively high, low and high levels of genetic variability. The more physically variable temperate marine environment supports populations of intermediate genetic variability, Valentine (1976), Ayala and Valentine (1978). A much better correlation exists with temporal variability in trophic resource availability. Where primary production is highly seasonal (arctic) genetic variability in invertebrates is low, where production is constant (tropics) variability is high. A causal link between these two factors has been proposed by Ayala and Valentine (1978). These theories have been criticised by Soulé (1976) because the proposed genotype-environment interactions have never been demonstrated. There is little evidence that heterozygosity leads to flexibility or trophic specialisation and there is a paucity of actual measurements of variability in relevant environmental parameters and its effect on fitnesses.

This paper describes a detailed study of two populations of the isopod Sphaeroma rugicauda (Leach) which differ in their level of colour polymorphism. Because this colour polymorphism affects fitness via physiological differences (Bishop, 1969; Heath, 1974; Khazaeli and Heath, 1979) it seemed reasonable to use it as a model for allozyme variability at least some of which is also known to act in this way (MacDonald, 1983). 
S. rugicauda is a common inhabitant of the intertidal saltmarshes of estuaries in Britain and Northern Europe and various aspects of its biology have been described (West, 1964; Harvey, 1969; Bishop, 1969; Heath, 1975a; Heath and Khazaeli, 1985). As far as this study is concerned the important features are as follows. The life cycle in Britain is annual, mating takes place in May and early June and the viviparous females release their young in late June and July. Animals die after breeding. Dessication in the summer and low salinity and low temperature in the winter are major sources of mortality amongst the offspring generation. British populations vary greatly in their degree of colour polymorphism (West, 1964; Heath, 1975b) although they characteristically have a common recessive form (Grey) and varying proportions of rarer 'colour' morphs (e.g., Red, Yellow, Pattern) controlled by dominant alleles at different loci. Not all morphs can be scored at birth some colour patterns taking 2-3 weeks to develop. The animals are probably scavengers/detritivores (Green, 1968; Willis, 1982).

\section{METHODS}

All methods are fully described by Willis (1982) so only the outlines are presented here.

\section{(i) Sampling}

Two populations which differed greatly in their degree of polymorphism were chosen for detailed study. The population at the River Deben, Suffolk (Map Reference TM 286501) was highly polymorphic compared to that at Alresford Creek, Essex (TM 082194) some $30 \mathrm{~km}$ to the south. The sites were similar in their vegetation cover, both being dominated by the grass Puccinellia maritima, but while the Essex site was at the head of the estuary at the extreme limits of tidal influence the Suffolk site was nearer to the sea. These two populations were sampled by net every month and the samples scored for colour morphs. Body lengths (of a random subsample) were measured and water salinity and temperature recorded at the sites on each sampling date.

It soon became apparent that individuals in the highly polymorphic Deben population were larger than those at Alresford. To further investigate the relationship between body size and polymorphism one sample was taken from each of a further 30 populations around the coast of Britain.

\section{(ii) Laboratory and field investigations on growth rate}

In the summer of 1980,100 random newly released offspring (=juveniles) were obtained from pregnant females taken from each of the two populations. Each juvenile was kept separately in a petri-dish of sea water with excess algae for food. Body length was measured every two weeks. Growth rate in the field was estimated in the summer of 1980 by confining animals in cages, following the method of Heath (1979). Thirty cages were placed on the marsh at Alresford Creek and 50 juveniles assigned at random to each cage. Ten cages received Alresford juveniles and 10 cages received Deben juveniles. A further 10 cages received Alresford animals but extra food, in the form of algae, was added every two weeks. Animals were recovered from the cages after three months, measured and scored for colour morphs. Time and resources did not allow the reciprocal experiment to be done at the Deben.

\section{(iii) Laboratory investigations into the relationship between survival, size and phenotype}

Initial investigations (Willis, 1982) showed that survival of large animals was significantly higher than that of small animals under conditions of (a) low temperature $\left(4^{\circ} \mathrm{C}\right)$ and low salinity $(2.5 \%)$ and (b) dessication.

Fifteen hundred juveniles were exposed to low temperature $\left(4^{\circ} \mathrm{C}\right)$ and low salinity $(5 \%)$ until there was approximately 50 per cent mortality. Another 500 juveniles were exposed to conditions of dessication known to cause about 50 per cent mortality. In both cases the survivors were grown up until colour morphs could be recognised and then scored. A further 450 juveniles were grown up under optimum conditions to act as a control. All three sets of juveniles were taken from the same sample drawn from the Deben population. This population was used because the higher "colour" morphs frequencies made it easier to detect changes.

To examine the effect of size and polymorphism on survival 30 sets of nine large animals (mean size $3.55 \mathrm{~mm}$ ) from the Deben were exposed to low temperature and salinity. Each set contained the same morphs in the ratio 3 Grey:3 pattern:2 Wine: 1 Yellow (or 1 Spotty). In both cases survivors were scored after three weeks when mortality was about 50 per cent. 
Table 1 Morph frequencies, mean body length, salinity and temperature for Alresford (A) and Deben (D) samples, October 1979-March 1982

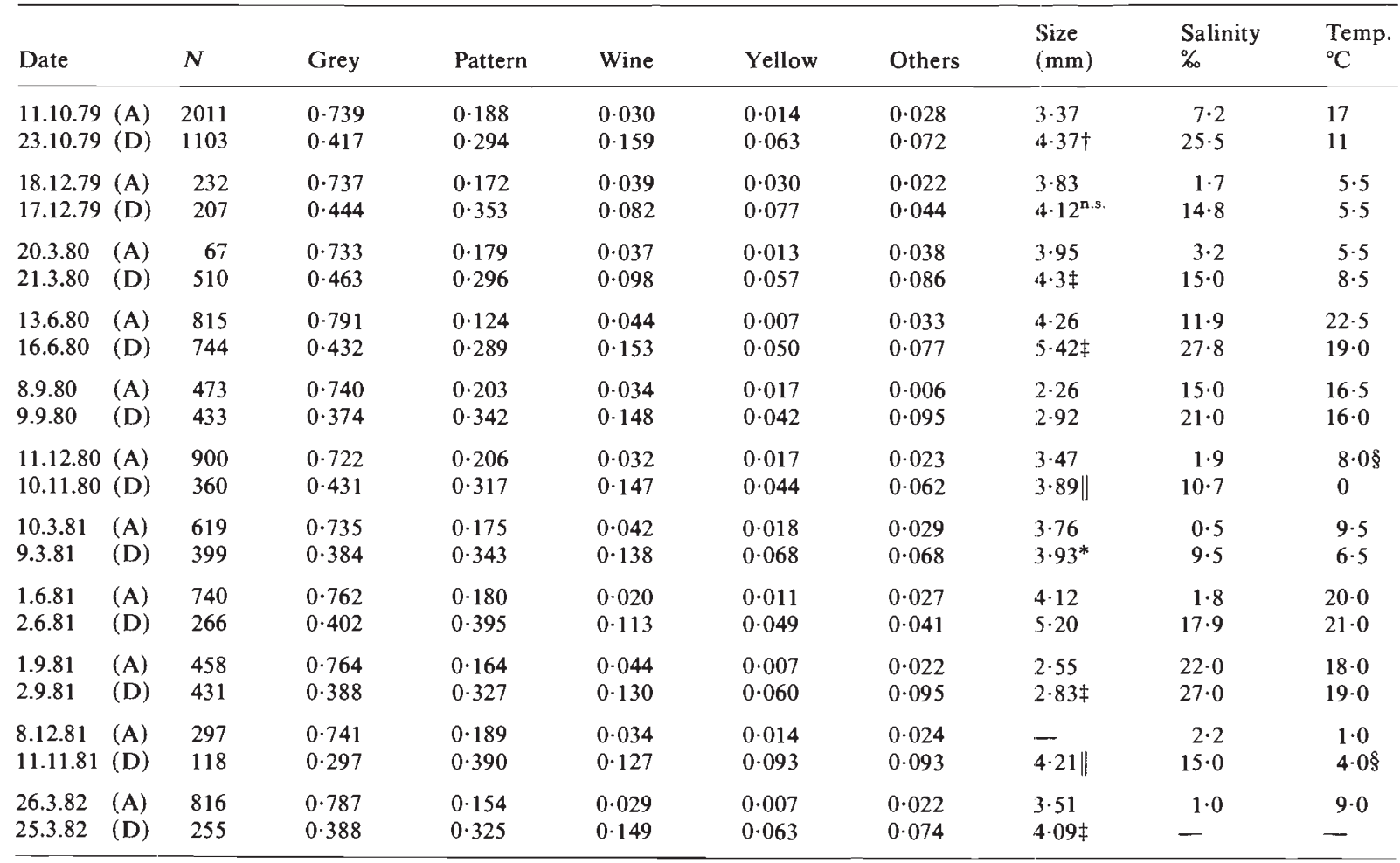

N, Sample size. - no data obtained.

$*, \dagger, \ddagger$ comparison of mean body lengths probabilities less than $0 \cdot 05.0 \cdot 01$ and 0.001 respectively.

$\S$ No data obtained for December, November data used.

$\|$ Difference in mean body length not tested.

\section{RESULTS}

\section{(i) Morph frequencies and average body length}

In the interests of brevity the data presented here are drawn arbitrarily from the full set given by Willis (1982) and are for the 3rd, 6th, 9th and 12th months of the years from 1979 to 1982 . The study began in October 1979, hence the inclusion of data for October rather than September in this year. No samples were obtained from the Deben in December 1980 and 1981 so the Deben samples nearest in time to the December Alresford samples are included. As will be described later the conclusions that can be drawn from this restricted data set are in no way contradicted by the full data set.

For every sample in table 1 the Deben population is more variable. In the Alresford population Grey was the predominant morph with frequencies always in excess of 70 per cent, Pattern varied between 12 and 20 per cent and Wine and Yellow occurred at frequencies of about 3 per cent and 1 per cent respectively. In the Deben population the frequency of Grey fluctuated around 40 per cent, Pattern around 30 per cent, Wine around 12 per cent and Yellow around 5 per cent. For each monthly comparison Grey was at a lower frequency at the Deben and the major colour morphs were at higher frequencies, compared to Alresford. The latter was also true of the category "others" which included the Stripe and Red morphs (Willis, 1982). In the full data set all monthly comparisons showed this property.

Average body length was lowest in the late summer when the population consisted mainly of juveniles, released in July. In every case Deben animals were larger, on average, than Alresford animals, usually significantly so. This picture is confirmed by the full data set in which 24 of the possible 29 comparisons show Deben animals to have had significantly greater mean body size. The conclusion is clear. The Deben population is more 
polymorphic and individuals are of larger average size. The size difference has been shown by Willis (1982) to be due to faster growth of juveniles at the Deben.

\section{(ii) Salinity and temperature}

The restricted data set shows that salinities in a given month were always higher at the Deben, the average salinity being $18 \cdot 42 \%$ compared to $6 \cdot 22 \%$ at Alresford. This is also true of the full data set which yields average values of $18.7 \%$ and $7.5 \%$ and ranges of $3 \cdot 5-27 \cdot 3 \%$ and $0 \cdot 5-22 \cdot 0 \%$ for the Deben and Alresford respectively. Salinities of less than $5 \%$ which are potent agents of mortality occurred on 14 occasions at Alresford but only once at the Deben.

By contrast the water temperatures at the two sites were very similar. The restricted data set (table 1) gives average values for the Deben and Alresford of $12.05^{\circ} \mathrm{C}$ and $11.05^{\circ} \mathrm{C}$ while the complete data set gives values of $11 \cdot 19^{\circ} \mathrm{C}$ and $11 \cdot 52^{\circ} \mathrm{C}$ with ranges of $1-24^{\circ} \mathrm{C}$ and $0-24^{\circ} \mathrm{C}$ respectively.

In terms of both the amount of variation and the level around which it occurs the two sites are similar for temperature. The amount of variation in salinity at the two sites is similar, but the variation occurs around a lower average at Alresford and extreme low values are more common.

(iii) Relationship between the degree of polymorphism and body size in 32 British populations

Fig. 1 shows the degree of polymorphism, calculated as $1-\Sigma p_{i}^{2}$, where $p_{i}$ is the frequency of the $i$ th morph (Greenwood, 1974) and average body length for samples from 32 populations. Because samples were taken at different times of the year average body lengths may not be directly comparable because of seasonal variation. To overcome this problem the average body length in a given sample is compared to the average body length in the Alresford population at the same time (as nearly as possible) as the given sample was taken. Average body length is then expressed as a percentage of the average Alresford body length.

There is a significant positive correlation between the two variables, the Spearman Rank Correlation Coefficient, $r_{s}=0.4755$, d.f. $30, p<$ $0 \cdot 01$. This confirms the finding from the comparison of Deben and Alresford animals that popu-

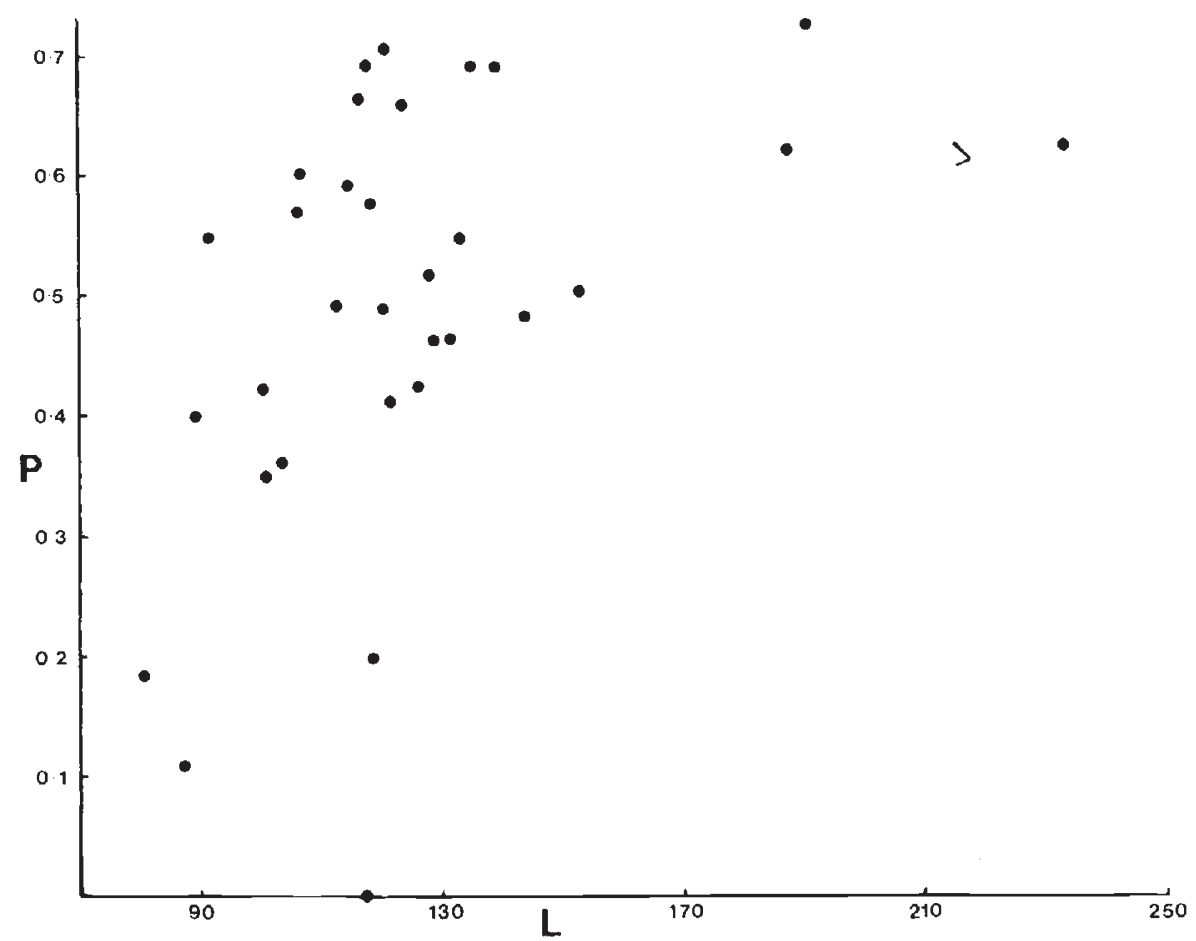

Figure 1 Index of polymorphism (P) plotted against L (average body length as a percentage of average body length at Alresford) for 32 samples from British populations. 
lations of large average body size tend to be more polymorphic.

\section{(iv) Growth rate in the field and laboratory}

Growth rate of juveniles from the two populations showed no significant differences, with no difference in mean size between the two groups (table 2). Deben and Alresford animals grown in the field at Alresford did not differ in size after 3 months and their mean size closely approximated that of the indigenous, uncaged, animals (table 3 ). In contrast, caged Alresford animals given additional food were significantly larger than both caged Alresford and caged Deben animals without a food supplement. These results clearly show that differences in body size between populations are primarily the result of environmental differences and that food availability is an important factor. Willis (1982) showed that there is twice as much organic material present in the substrate at the Deben.

Interestingly the morph frequencies of caged Deben animals were significantly different from the uncaged Deben animals. Grey had increased in frequency at the expense of "Other" morphs (i.e., Wine, Yellow, Stripe and Red, pooled because of the small numbers involved). These frequencies now resembled typical Alresford frequencies.

Table 2 Mean body length of Deben and Alresford animals after 8 weeks growth in the laboratory

\begin{tabular}{llllll}
\hline & $\begin{array}{l}\text { Initial } \\
\text { size } \\
(\mathrm{mm})\end{array}$ & $\begin{array}{l}\text { Final } \\
\text { size } \\
(\mathrm{mm})\end{array}$ & $\mathrm{N}$ & $\begin{array}{l}\text { Standardised } \\
\text { Normal } \\
\text { Deviate } \\
(\mathrm{d})\end{array}$ & $\mathrm{p}$ \\
\hline Deben & 1.38 & 5.68 & 95 & 1.416 & n.s. \\
Alresford & 1.36 & 5.50 & 99 & & \\
\hline
\end{tabular}

\section{(v) Survival of different morphs in} the laboratory

Morph frequencies amongst survivors and control animals are given in table 4(a). In both the low salinity/low temperature treatment and the dessication treatment Grey increased significantly in frequency particularly at the expense of "Other" (i.e., not-Pattern) morphs.

As can be seen from table 4(b) large animals survive better than small $\left(\chi^{2}=28 \cdot 22\right.$, d.f. $1, p<$ $0 \cdot 001)$. While morph frequencies amongst large survivors were very similar to initial frequencies there was some evidence of a change in frequencies amongst small bodied survivors with Grey more common and Pattern and Others less common. These differences were not significant when the pooled numbers were tested by $\chi^{2}$ but this test loses some of the information from the original replicates. From the original data given by Willis (1982) it is possible to analyse the direction and magnitude of the change in frequency of Grey in the 30 replicates of small animals using the Wilcoxon signed rank test (Siegel, 1956). Grey increased in frequency in 17 replicates, decreased in seven and did not change in six. This gave a

Table 4

(a) Survival of different morphs under low salinity and temperature and dessication

\begin{tabular}{llllll} 
Treatment & Grey & Pattern & Others & $\mathrm{N}$ & $\mathrm{p}$ \\
\hline Low Salinity/Low & & & & & \\
$\quad$ temp. & 0.402 & 0.406 & 0.192 & 625 & $<0.001$ \\
Control & 0.314 & 0.396 & 0.290 & 414 & $<0.05$ \\
Dessication & 0.402 & 0.364 & 0.234 & 316 &
\end{tabular}

(b) Effect of size on survival and polymorphism

$\begin{array}{lllll}\text { Small } & 0.424 & 0.288 & 0.288 & 125 \\ \text { Initial } & 0.333 & 0.333 & 0.333 & 270 \\ \text { Large } & 0.355 & 0.317 & 0.328 & 186\end{array}$

Table 3 Mean body length and morph frequencies for Alresford and Deben animals in cages at Alresford and for indigenous, uncaged animals

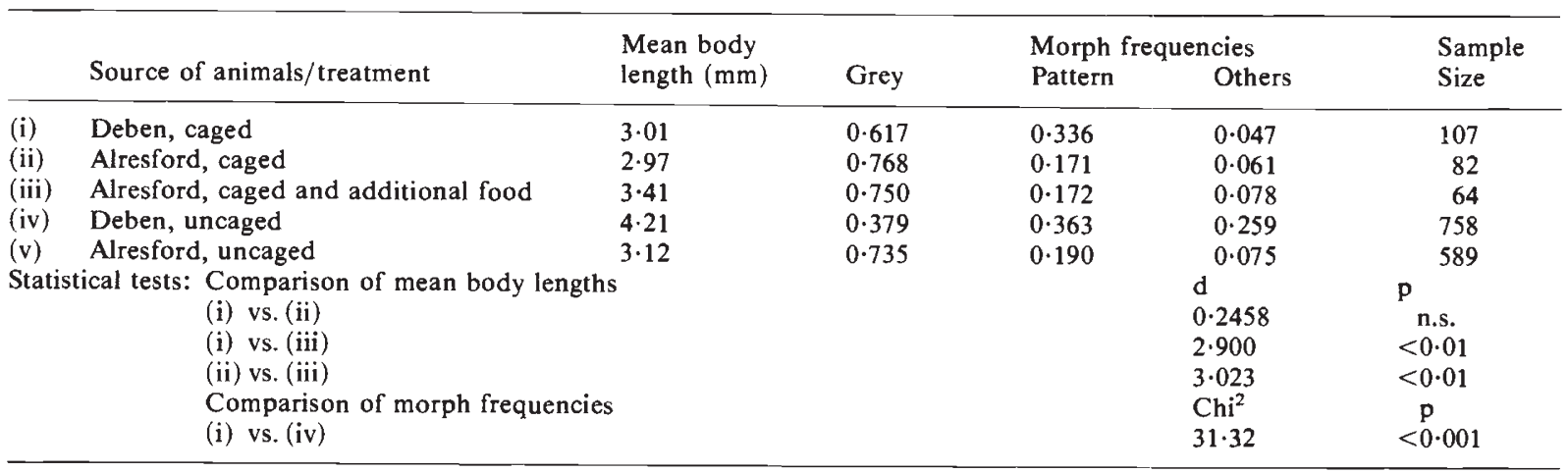


value of $T=44$ for $n=24$ and an associated probability less than 0.005 . A similar analysis of the results for the large bodied animals gave $T=74$, $n=21$ and was not significant.

Under these stressful conditions the advantage to individuals of the Grey morph depends upon their size. At small body sizes they are at an advantage but this disappears at larger body sizes. The experiments described in table 3 and 4(a) which also showed enhanced survival of Grey were all initiated with very small (newly born) animals and are thus compatible with the results in $4(\mathrm{~b})$.

\section{DISCUSSION}

These results confirm those of other studies on colour polymorphism in Sphaeroma and other isopods, in that populations vary greatly in their colour morph frequencies e.g., West (1964) and Heath (1975b) for S. rugicauda, Hoestlandt (1955) for S. serratum and Saleema (1979) for Idotea baltica. Also, according to the last three authors, where environmental conditions were inferred to be variable or stringent (as in peripheral populations) genetic variability was reduced. Similar reductions in genetic variability have been reported in the marine copepods Porcellidium fimbriatum and Tisbe reticulata by Battaglia et al. (1978).

The polymorphism in $S$. rugicauda is clearly adaiptive in the sense that colour morphs differ in fitness, as assessed by their survival under adverse physical conditions. Similar results have been described for S. rugicauda by Bishop (1969), Heath (1974) and Khazaeli and Heath (1979). In the latter two cases winter conditions of low salinity and temperature were found to favour the Grey morph over Yellow and Pattern, results clearly consistent with those described here, where the Grey morph has been shown to be the more flexible and the best adapted to survival under extreme conditions. Survival differences appear to have no direct relation to the colour differences but are presumably physiologically mediated via pleiotropic effects of the colour genes. This contrasts with the situation in $I$. baltica where the reduction in colour polymorphism is attributed to changes in the background mosaic of algae and epizooites caused by variation in abiotic factors (Saleema, 1979).

As Marsden (1973) and Khazaeli and Heath (1979) found, mortality due to salinity stress was greatest in small animals, presumably due to less favourable surface area to mass ratios. Large individuals will therefore experience a harsh and variable environment as less stressful than will small animals as Selander and Kaufman (1973) proposed. Not only are mortality rates overall related to size but so are the fitness differences. These are undetectable between phenotypes in large individuals but are clearly demonstrable in small individuals. Since selection against non-Grey is reduced in large animals, populations consisting of larger animals might be expected to be more variable than those consisting of smaller individuals. This holds true for the two populations studied in detail and for populations generally. Size differences between the two populations were at least partly due to food availability since the addition of food decreased the size difference. Willis (1982) has shown that, compared to Alresford, there is twice as much organic material present in the surface layers of the substrate at the Deben. This may represent a greater food supply for a detritivore such as Sphaeroma. Thus the availability of food, via its effect on growth rate and body size, alters the relative survival rates of the morphs and hence the degree of polymorphism. What actually maintains the polymorphism is still obscure. Heterozygous advantage (Bishop, 1969) and a balance of opposing seasonal selective forces (Bishop, 1969; Heath, 1974) have been proposed but not rigorously investigated.

Given that the colour polymorphism in $S$. rugicauda affects physiology it is valid to interpret our results in the context of the theories described in the introduction, although these were developed to explain observed relationships between biochemical (allozyme) variability and ecological factors.

In terms of temporal variation in temperature and salinity the two sites described were equally variable, and although spatial heterogeneity was not investigated the same plant species dominated both sites which suggests little difference between them in this respect. However the two populations differed in genetic variability. This does not support the "hetero selection" theory of Grasslé (1972) nor the general idea of Levins (1969) that levels of genetic variability are determined by environmental variability. The results also contradict the prediction of Selander and Kaufman (1973) that body size and levels of genetic variability are negatively correlated. Differences in the seasonal pattern of trophic resource availability will be negligible between two sites at essentially the same latitude rendering this an unlikely explanation. In addition as Valentine (1976) points out seasonal variation in food supply is likely to be much less for detritivores.

The demonstration that the Grey (homozygote) produced the most flexible phenotype supports the 
suggestion by Battaglia (1959) that in a more exacting environment phenotypic flexibility could be achieved by fixation of a few "generalist" alleles rather than by heterozygosity, confirmed by the demonstration (Battaglia et al., 1978) that (electrophoretic) genetic variability in copepod species was lower in more exacting environments. Their study did not distinguish clearly whether a rock pool environment was to be considered more exacting (than a marine environment) because it was more variable or because it was sometimes extreme. This relationship between extremeness and the variability of an environment has never been fully discussed and neither has the effect of environmental extremes on genetic variability been explored experimentally. Variable environments need not necessarily embrace extreme conditions (e.g., temperature in temperate seas) while constant environments may well occur at extremes (e.g., thermal springs, hypersaline lakes, polar seas). By definition the most variable environments (e.g., rock pools) will sometimes be extreme. From our work it appears that the level of genetic variability is determined, not by environmental variability, but by the occurrence of extreme conditions. The more frequent low salinities at Alresford by reducing the survival of non-Grey morphs reduce the level of genetic variability. This effect, and that of dessication is further enhanced by the differences in size between animals. This means that, even if the abiotic environments at the two sites were to be the same, the smaller animals at Alresford would experience their environment as more extreme. We propose that extreme conditions, whether temporally intermittent or continuous, can only be tolerated by a restricted range of genotypes which have the necessary biochemical/physiological flexibility.

The correlation between environmental extremes and genetic variability is based on a detailed study of only two populations; data from several would be required to test whether this was general. However, the correlation between body size and genetic variability in 32 populations and the causal links demonstrated by the experiments on mortality under extreme conditions give added support to the theory.

It is the occurrence of extreme conditions which primarily determines the overall level or (non-neutral) genetic variability, although the level may then be modulated by (a) spatial or temporal environmental variability and (b) organism size. Such an explanation seems to provide a reasonable alternative to that of "trophic resource availability" hypothesis, especially as it shifts the emphasis on the mode of action of mainly intracellular enzyme variants from "trophic" physiology to general physiology. On this new hypothesis populations in extreme environments of low variability (e.g., polar) seas should have low variability; constant, non-extreme environments (tropical seas) should support populations with high genetic variability and highly variable and sometimes extreme environments, such as the temperate intertidal zone should show intermediate levels of genetic variability. The deep sea is a non variable environment but at least in terms of temperature is less extreme than, for example, polar waters. Water temperatures at 2000 metres are between $3-4^{\circ} \mathrm{C}$ Kinne (1970) while surface antarctic waters may be at at $-1 \cdot 8^{\circ} \mathrm{C}$. Deep sea populations should have reasonably high levels of genetic variability. This, broadly speaking, is the pattern that is found.

Acknowledgements This work was carried out under an N.E.R.C. Research Studentship awarded to M.J.W.

\section{REFERENCES}

AYALA, F. J. AND VALENTINE, J. W. 1978. Genetic variation and resource stability in marine invertebrates. In Battaglia, B. and Beardmore, J. A. (eds.) Marine Organisms: Genetics, Ecology and Evolution. Plenum, New York, pp. 23-51.

BATTAGLIA, B. 1958. Balanced polymorphism in Tisbe reticulata, a marine copepod. Evolution, 12, 358-364.

BATTAGLIA, B., BISOL, P. M. AND FAVA, G. 1978. Genetic variability in relation to the environment in some marine invertebrates. In Battaglia, B. and Beardmore, J. A. (eds.) Marine Organisms: Genetics, Ecology and Evolution. Plenum, New York, pp. 53-69.

BISHOP, J. A. 1969. Changes in genetic constitution of a population of Sphaeroma rugicauda (Crustacea: Isopoda). Evolution, 23, 589-601.

GRASSLÉ, J. F. 1972. Species diversity, genetic variability and environmental uncertainty in Fifth European Marine Biological Symposium, Piccin Editore, Padua, pp. 19-26.

GREEN, J. 1968. The Biology of Estuarine Animals. Sidgwick and Jackson, London.

GREENWOOD, J. D. 1974. Visual and other selection in Cepaea. A further example. Heredity, 33, 17-31.

HARVEY, C. E. 1969. Breeding and distribution of Sphaeroma (Crustacea: Isopoda) in Britain. J. Anim. Ecol., 38, 399-406.

HEATH, D. J. 1974. Seasonal changes in frequency of the "Yellow" morph of the isopod Sphaeroma rugicauda. Heredity, 32, 299-307.

HEATH, D. J. 1975a. Factors affecting temperature and salinity conditions on a Scottish saltmarsh with notes on the ecology of Sphaeroma rugicauda, Archiv. fur Hydrobiologie, $75,76-89$.

HEATH, D. J. 1975b. Geographical variation in populations of the polymorphic isopod, Sphaeroma rugicauda. Heredity, 35, 99-107.

HEATH, D. J. 1979. Colour polymorphism in the salt-marsh isopod, $S$. phaeroma rugicauda; evidence for stable equilibrium frequencies. Oecologia, 44, 95-97.

HEATH, D. J. AND KHAZAELI, A. A. 1985. Population dynamics of the estuarine isopod, Sphaeroma rugicauda. Estuarine Coastal \& Shelf Sci., 20, 105-116. 
HEDRICK, P. W., GINEVAN, M. E. AND EWING, E. P. 1976. Genetic polymorphism in heterogeneous environments. Ann. Rev. Ecol. Syst., 7, 1-32.

HOESTLANDT, H. 1955. Etude de populations de Sphaeroma serratum le long de la Grande Bretagne. C.R. Acad. Sci., 240, 916-919.

KHAZAEl, A. A. AND HEATH, D. J. 1979. Colour polymorphism, selection and the sex ratio in the isopod Sphaeroma rugicauda (Leach). Heredity, 41, 187-199.

KINNE, O. 1970. Temperature. In Kinne, O. (ed.) Marine Ecology. Volume 1. Wiley Interscience. pp. 321-346.

LEVINS, R. 1968. Evolution in Changing Environments. Princeton University Press, Princeton.

McDONALD, J. F. 1983. The molecular basis of adaptation: a critical review of relevant ideas and observations. Ann. Rev. Ecol. Syst., 14, 77-102.

MARSDEN, I. 1973. The influence of salinity and temperature on the survival and behaviour of the isopod Sphaeroma rugicauda from a salt-marsh habitat. Mar. Biol, 21, 75-85.
SALEEMA, H. 1978. Geographic variability in the colour polymorphism of Idotea baltica (Isopoda) in the Northern Baltic. Hereditas, 88, 165-182.

SELANDER, R. K. AND KAUFMAN, D. W. 1973. Genic variability and strategies of adaptation in animals. Proc. Natl. Acad. Sci. U.S.A., 70, 1875-1877.

SIEGEL, S. 1956. Nonparametric statistics for the behavioural Sciences. McGraw-Hill, New York.

SOULÉ, M. 1976. Allozyme variation: its determinants in space and time in Ayala, F. J. (ed.) Molecular Evolution. Sinauer Associates, Inc. Sunderland, Massachusetts, pp. 60-77.

VALENTINE, J. W. 1976. Genetic strategies of adaptation. In Ayala, F. J. (ed.) Molecular Evolution. Sinauer Associates, Inc. Sunderland, Massachusetts. 78-94.

WEST, D. A. 1964. Polymorphism in the isopod, Sphaeroma rugicauda. Evolution, 18, 671-684.

WILLIS, M. J. 1982. Factors affecting levels of colour polymorphism in the isopod, Sphaeroma rugicauda (Leach). Ph.D. Thesis, University of Essex. 